\title{
TATA KELOLA TEKNOLOGI INFORMASI MENGGUNAKAN KERANGKA KERJA COBIT 5 PADA PT. NAPOL MEDAN BERKAH
}

\author{
Aninda Muliani, Zein Ahmad Fachrurrozi, Qisi Desika Kirana, Abu Dardaq Putra \\ Universitas Islam Negeri Sumatera Utara \\ J1. IAIN No.1 Medan \\ e-mail: anindamh@uinsu.ac.id, zein.master20@gmail.com,desikaqisy@gmail.com, \\ abudardaqputra@gmail.com
}

\begin{abstract}
PT. Napol Medan Berkah is a company engaged in retail souvenirs from the city of Medan in the form of Napoleon Cake. PT. Napol Medan Berkah always efforts to provide optimal services to people by improving services using Information Technology which is expected to simplify the service process and improve service quality. Therefore, an analysis of the information technology governance system is carried out at the company. In analyzing the current level of information technology process capability and the expected level of information technology process capability, an information technology management method is carried out using the COBIT framework. The process used in this research is EDM04 and APO11. PT Napol Medan Berkah has implemented information technology governance at the Defined Process level. The results of data processing found that the average value for the capability level was 3.9 from a value range of 0 to 5. This means that PT Napol Medan Berkah has carried out good information technology governance.
\end{abstract}

Keywords: information technology governance, COBIT 5, framework, domain.

\begin{abstract}
Abstrak. PT. Napol Medan Berkah merupakan perusahaan yang bergerak dalam bidang retail oleh-oleh Kota Medan berupa Napoleon Cake. PT. Napol Medan Berkah ingin memberikan layanan yang optimal, sehingga dapat meningkatkan pelayanan dengan menggunakan Teknologi Informasi yang diharapkan dapat mempermudah proses pelayanan dan memingkatkan mutu pelayanan. Maka dari itu dilakukan analisa pada system tata kelola teknologi informasi pada perusahaan tersebut. Dalam menganalisa tingkat kapabilitas proses teknologi informasi saat ini dan tingkat kapabilitas proses teknologi informasi yang diharapkan., maka dilakukan metode pengelolaan teknologi informasi menggunakan kerangka kerja COBIT. Proses yang digunakan dalam penelitian ini adalah EDM04 dan APO11. PT Napol Medan Berkah telah menerapkan tata kelola teknologi informasi pada level Defined Process. Hasil pengolahan data mendapati nilai rata-rata untuk tingkat kapabilitas adalah 3,9 dari rentang nilai 0 sampai 5. Artinya PT Napol Medan Berkah telah melakukan tata kelola teknologi informasi dengan baik.
\end{abstract}

Kata kunci: tata kelola teknologi informasi, COBIT 5, framework, domain.

\section{Pendahuluan}

Tata Kelola Teknologi Informasi ada karena peran Teknologi Informasi semakin tinggi dalam membangun dan meningkatkan kinerja suatu perusahaan. Tata Kelola Teknologi Informasi diterapkan agar kinerja teknologi informasi dapat diarahkan dan sesuai dengan tujuan perusahaan. Selain Tata Kelola Teknologi Informasi, pelayanan terkait teknologi informasi itu sendiri merupakan unsur terpenting yang harus diperhatikan oleh perusahaan. Pelayanan (service) juga dinilai sebagai faktor pendorong kesuksesan perusahaan.

Sebagai salah satu unsur yang sangat penting, maka setiap perusahaan akan berusaha semaksimal mungkin memberikan pelayanan terbaik untuk para pelanggan. Terlebih-lebih pada era digital seperti sekarang, perusahaan mencoba menarik simpati pelanggan dengan menggunakan layanan teknologi informasi yang dapat mempermudah pelanggan dan meningkatkan kualitas perusahaan di mata pelanggannya. Begitu juga dengan PT. Napol Medan Berkah yang ingin memberikan layanan yang optimal, salah satunya dengan meningkatkan pelayanan teknologi informasi yang diharapkan dapat meningkatkan mutu pelayanan perusahaan.

Dalam penelitian ini standar tata kelola yang digunakan adalah COBIT 5. Standar COBIT 
dipilih karena kerangka kerja COBIT memberikan gambaran paling detail mengenai strategi dan control dalam pengaturan proses sistem informasi yang mendukung keselarasan strategi bisnis dan tujuan teknologi informasi.

COBIT 5 merupakan sebuah kerangka kerja atau panduan tata kelola dan manajamen teknologi informasi serta semua yang berhubungan, dimulai dengan memenuhi kebutuhan stakeholder akan informasi dan teknologi. COBIT 5 menyediakan kerangka kerja komprehensif yang membantu perusahaan dalam mencapai tujuan mereka untuk pemerintahan dan manajemen TI perusahaan. Secara sederhana, hal ini membantu perusahaan menciptakan nilai $\mathrm{TI}$ yang optimal dengan menjaga keseimbangan antara mewujudkan manfaat TI dan meminimalkan tingkat resiko dan penggunaan sumber daya. COBIT 5 memungkinkan TI untuk diatur dan dikelola secara holistik dengan mengambil penuh bisnis end-to-end dan tanggung jawab IT area secara fungsional, mengingat TI merupakan hal yang penting bagi pemangku kepentingan internal dan eksternal. COBIT 5 bersifat generik dan berguna untuk perusahaan dari semua ukuran, baik yang komersial, non-profit atau di sektor publik (ISACA, 2012).

Framework COBIT 5dirancang dengan 5 domain dan masing-masing mencakup penjelasan rinci dan luas yang bertujuan sebagai tata kelola dan manajemen TI perusahaan. Lima domain yang ada pada COBIT 5, yaitu:

a. EDM (Evaluate, Direct and Monitor)

b. APO (Align, Plan and Organise)

c. BAI (Build, Acquire and Implement)

d. DSS (Deliver, Service, and Support)

e. MEA (Monitor, Evaluate and Assess)

\section{Metode Penelitian}

\subsection{Tahapan Penelitian}

Berikut adalah tahapan penelitian yang digunakan :

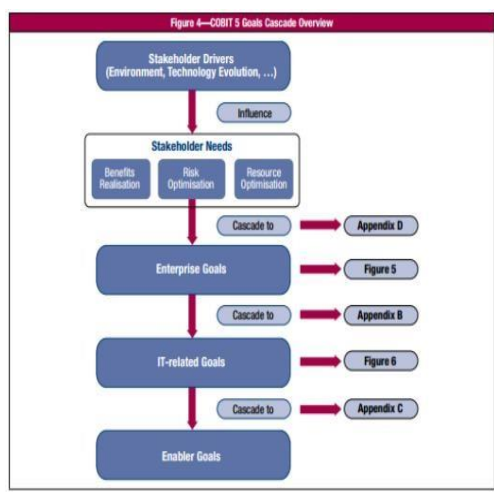

Gambar 1. Tahapan Penelitian

\subsection{Pengumpulan Data}

Pengumpulan data dilakukan dengan cara pengisian kuesioner. Kuesioner yang diberikan dirancang untuk mengetahui tingkat kematangan pengelolaan teknologi informasi, khususnya bagian sistem pelayanan, yang telah digunakan PT. Napol Medan Berkah dan dengan melihat tanggapan pengguna dan pembuatan saran teknologi informasi melalui perbandingan antara kondisi saat ini dengan harapan di masa mendatang.

Kuesioner berisi beberapa pernyaataan mewakili Awareness, policies, tools, skills, responsibility dan goals yang terbagi dalam dua bagian yaitu tanggapan akan kondisi saat ini (as-is) dengan kondisi yang diharapkan (to-be). Masingmasing penilaian memiliki 6 tingkat nilai yang berbobot antara 0 sampai dengan 5 sesuai dengan dasar yang terdapat pada model COBIT. Responden yang dipilih adalah responden yang mewakili tabel RACI (Responsibility, Accountability, Consult, and Inform) pada proses pengolahan data RACI Chart.

\subsection{Perencanaan Tata Kelola TI}

Perencanaa tata kelola teknologi infomasi, antara lain:

a. Perencanaan tata kelola dibuat dengan mempertimbangkan rencana perbaikan yang diperlukan terhadap proses-proses teknologi informasi.

b. Rencana perbaikan berisi rekomendasirekomendasi yang harus dilakukan oleh perusahaan dengan tujuan memberi arahan kepada pihak manajemen agar dapat mencapai target tingkat kapabilitas proses teknologi informasi yang diharapkan.

c. Pembuatan model tata kelola diwujudkan dalam bentuk penyusunan usulan kebijakan perusahaan terkait dengan teknologi informasi pada PT. Napol Medan Berkah.

\subsection{Analisis Data}

Analisis data merupakan sebuah upaya pengolahan data menjadi informasi baru dengan tujuan karakteristik data itu menjadi lebih mudah dimengerti dan bisa menjadi solusi bagi sebuah permasalahan. Analisis data meliputi pengumpulan data, penyajian data, reduksi data, interprestasi data, dan penarikan simpulan.

a. Analisis Tingkat Kematangan saat ini

Dari hasil jawaban kuesioner dan hasil wawancara dari narasumber pada instansi yang diperoleh, maka analisis yang dilakukan pada tahap ini adalah untuk menilai tingkat kematangan tata kelola teknologi informasi pada aktivitas EDM04 dan APO011, akan tersedia jawaban dengan nilai $0-5$. 
b. Analisis Tingkat Kematangan yang diharapkan Tingkat kematangan yang dimaksud adalah kondisi ideal dari proses TI yang diharapkan. Tingkat kematangan ini menjadi acuan dalam tata Kelola TI pada sistem informasi PT. Napol Medan Berkah.

\section{Hasil dan Pembahasan}

\subsection{Identifikasi Domain COBIT}

Pada tahap ini ditenentukan proses domain dan subdomain pada COBIT 5 dengan masalah yang ada pada PT. Napol Medan Berkah. a. Enterprise Goals

Tujuan perusahaan ini adalah budaya inovasi produk dan bisnis (17)

b. IT-Related Goals

Terdapat dua tujuan IT pada perusahaan ini, yaitu:

1) Kelincahan IT

2) Pengetahuan, keahlian dan inisiatif untuk inovasi bisnis

c. Domain dan Subdomain
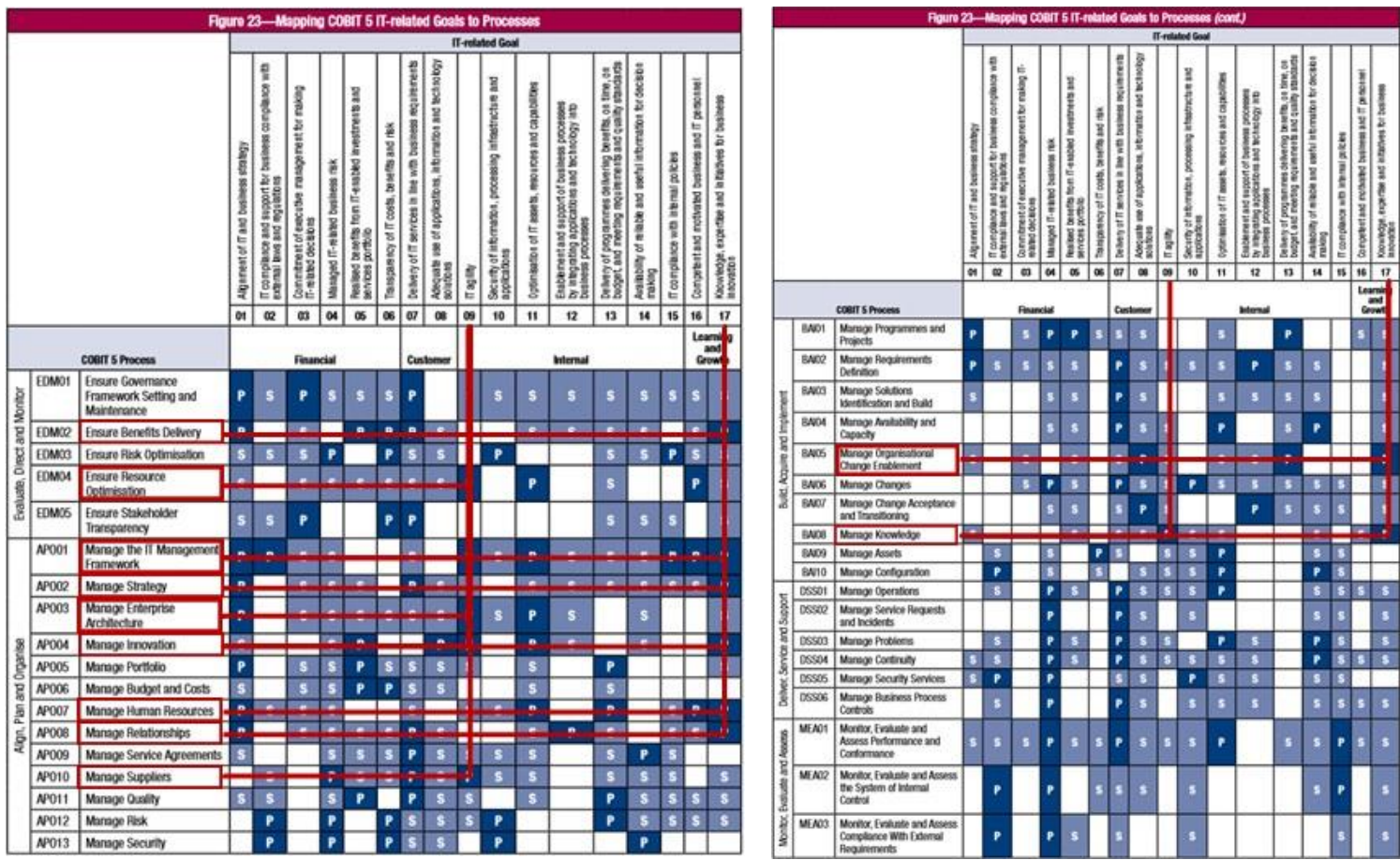

Gambar 2 dan 3. Penentuan Domain

1) EDM04 : Pastikan Optimalisasi Sumber Daya

Subdomain :

a) EDM04.01 Mengevaluasi manajemen sumber daya

b) EDM04.02 Mengarahkan manajemen sumber daya

c) EDM04.03 Memonitor manajemen sumber daya

2) APO11: Kelola Kualitas

Subdomain :

a) APO11.01 Membangun manajemen

b) kualitas

c) APO11.02 Menentukan dan mengelola standar kualitas

d) APO11.03 Fokuskan manajemen kualitas pada pelanggan e) APO11.04 Melakukan pemantauan, control, dan peninjauan kualitas layanan

f) APO11.05 Mengintegrasikan manajemen kualitas untuk pengembangan dan pemberian

g) APO11.06 Mempertahankan peningkatan berkelanjutan

\subsection{Pengolahan Data}

Berdasarkan pemilihan proses COBIT yang telah dijelaskan, terdapat 6 proses COBIT yang diukur tingkat kapabilitasnya. Dalam melakukan proses penilaian, masing-masing proses dinilai secara bertahap mulai dari level 1 hingga level 5 . 


\subsubsection{Hasil Rekapitulasi Jawaban Kuesioner}

a. Hasil Rekapitulasi Jawaban Kuesioner EDM04

Tabel 1. Rekapitulasi Jawaban Kuesioner EDM04

\begin{tabular}{|c|c|c|c|c|c|c|c|c|}
\hline \multirow{2}{*}{ No } & \multirow{2}{*}{ Aktivitas } & \multirow{2}{*}{ Status } & \multicolumn{6}{|c|}{ Distribusi Jawaban (\%) } \\
\hline & & & 0 & 1 & 2 & 3 & 4 & 5 \\
\hline \multirow{2}{*}{1.} & \multirow{2}{*}{$\begin{array}{l}\text { Memeriksa dan membuat } \\
\text { penilaian dan strategi dimasa } \\
\text { depan dengan opsi } \\
\text { menyediakan sumber daya IT } \\
\text { dan mengembangkan } \\
\text { kemampuan serta memenuhi } \\
\text { kebutuhan saat ini dan } \\
\text { kebutuhan masa depan } \\
\text { (termasuk pilihan sumber } \\
\text { daya). }\end{array}$} & As is & 0 & 0 & 0 & 40 & 60 & 0 \\
\hline & & To be & 0 & 0 & 0 & 0 & 0 & 100 \\
\hline \multirow{2}{*}{2.} & \multirow{2}{*}{$\begin{array}{l}\text { Menentukan prinsip untuk } \\
\text { keperluan alokasi dan } \\
\text { pengelolaan sumber daya } \\
\text { kemampuan TI dan memenuhi } \\
\text { kebutuhan perusahaan dengan } \\
\text { kemampuan dan kapasitas } \\
\text { sesuai dengan prioritas yang } \\
\text { disepakati. }\end{array}$} & As is & 0 & 0 & 40 & 40 & 20 & 0 \\
\hline & & To be & 0 & 0 & 0 & 0 & 0 & 100 \\
\hline \multirow{2}{*}{3.} & \multirow{2}{*}{$\begin{array}{l}\text { Meninjau rencana sumber daya } \\
\text { dan strategi perusahaan untuk } \\
\text { memberikan nilai dan } \\
\text { mengurangi risiko dengan } \\
\text { sumber daya yg dialokasikan. }\end{array}$} & As is & 0 & 0 & 0 & 40 & 60 & 0 \\
\hline & & To be & 0 & 0 & 0 & 0 & 0 & 100 \\
\hline \multirow{2}{*}{4.} & \multirow{2}{*}{$\begin{array}{l}\text { Memahami persyaratan untuk } \\
\text { menyelaraskan manajemen } \\
\text { sumber daya dengan } \\
\text { perencanaan keuangan dan } \\
\text { sumber daya manusia (SDM) } \\
\text { perusahaan. }\end{array}$} & As is & 0 & 0 & 20 & 20 & 40 & 20 \\
\hline & & To be & 0 & 0 & 0 & 0 & 0 & 100 \\
\hline \multirow{2}{*}{5.} & \multirow{2}{*}{$\begin{array}{l}\text { Menetapkan prinsip- prinsip } \\
\text { untuk manajemen dan kontrol } \\
\text { arsitektur perusahaan. }\end{array}$} & As is & 0 & 0 & 20 & 40 & 40 & 0 \\
\hline & & To be & 0 & 0 & 0 & 0 & 0 & 100 \\
\hline \multicolumn{3}{|c|}{ Kondisi saat ini } & 0 & 0 & 16 & 36 & 44 & 4 \\
\hline \multicolumn{3}{|c|}{ Kondisi yang diharapkan } & 0 & 0 & 0 & 0 & 0 & 100 \\
\hline
\end{tabular}

b. Hasil Rekapitulasi Jawaban Kuesioner APO11

Tabel 2. Rekapitulasi Jawaban Kuesioner APO11

\begin{tabular}{|c|c|c|c|c|c|c|c|c|}
\hline \multirow{2}{*}{ No } & \multirow{2}{*}{ Aktivitas } & \multirow{2}{*}{ Status } & \multicolumn{6}{|c|}{ Distribusi Jawaban (\%) } \\
\hline & & & $\mathbf{0}$ & 1 & 2 & 3 & 4 & 5 \\
\hline \multirow{2}{*}{1.} & \multirow{2}{*}{$\begin{array}{l}\text { Menetapkan praktik dan } \\
\text { prosedur standar manajemen } \\
\text { perusahaan sesuai kualitas } \\
\text { dengan kerangka kerja kendali } \\
\text { TI yang digunakan. }\end{array}$} & As is & 0 & 0 & 0 & 20 & 40 & 40 \\
\hline & & To be & 0 & 0 & 0 & 0 & 0 & 100 \\
\hline \multirow{2}{*}{2.} & \multirow{2}{*}{$\begin{array}{l}\text { Mempertimbangkan manfaat } \\
\text { dan biaya kualitas sertifikasi } \\
\text { untuk perusahaan. }\end{array}$} & As is & 0 & 0 & 0 & 0 & 40 & 40 \\
\hline & & To be & 0 & 0 & 0 & 0 & 0 & 100 \\
\hline \multicolumn{3}{|c|}{ Kondisi saat ini } & 0 & 0 & 0 & 10 & 40 & 40 \\
\hline \multicolumn{3}{|c|}{ Kondisi yang diharapkan } & 0 & 0 & 0 & 0 & 0 & 100 \\
\hline
\end{tabular}




\subsubsection{Penentuan Nilai dan Tingkat Kapabilitas} Berdasarkan rekapitulasi jawaban kuesioner, kemudian dicari nilai rata-rata tingkat kapabilitas masing-masing proses yang dimililiki oleh PT. Napol Medan Berkah

a. Tingkat Kapabilitas EDM04

Tabel 3. Tingkat Kapabilitas EDM04

\begin{tabular}{|c|c|c|c|c|c|}
\hline \multirow{2}{*}{ No } & \multirow{2}{*}{ Sub Proses } & \multicolumn{2}{|c|}{ Nilai Kapabilitas } & \multicolumn{2}{|c|}{ Tingkat Kapabilitas } \\
\hline & & As is & To be & As is & To be \\
\hline 1. & EDM04.01 & 3,8 & 5 & 4 & 5 \\
\hline 2. & EDM04.02 & 3,68 & 5 & 4 & 5 \\
\hline 3. & EDM04.03 & 4,3 & 5 & 4 & 5 \\
\hline & Rata-rata & 3,9 & 5 & 4 & 5 \\
\hline
\end{tabular}

Dari tabel di atas dapat disimpulkan bahwa pada proses ensure resource optimisation di PT. Napol Medan Berkah untuk kondisi saat ini (as is) memperoleh nilai 3,9 atau bisa dikatakan berada di tingkat kapabilitas level 4 yaitu Predictable Process. Artinya pada pada proses EDM04 (Ensure Resource Optimisation) di PT. Napol Medan Berkah beroperasi dalam batas yang ditentukan untuk mencapai hasil prosesnya. Sedangkan, untuk kondisi yang diharapkan (to be) pada proses ensure resource optimisation di PT. Napol Medan Berkah memperoleh nilai 5 dengan tingkat kapabilitas level 5 yang dimana pada tahap ini harus diterapkan Optimising Process. Artinya pada proses EDM04 (Ensure Resource Optimisation) di PT. Napol Medan diharapkan terus ditingkatkan menjadi memenuhi sasaran dan relevan dengan bisnis saat ini.

\section{b. Tingkat Kapabilitas APO11}

Tabel 4. Tingkat Kapabilitas APO11

\begin{tabular}{|c|c|c|c|c|c|}
\hline \multirow{2}{*}{ No } & \multirow{2}{*}{ Sub Proses } & \multicolumn{2}{|c|}{ Nilai Kapabilitas } & \multicolumn{2}{|c|}{ Tingkat Kapabilitas } \\
\hline & & As is & To be & As is & To be \\
\hline 1. & APO11.01 & 3,85 & 5 & 4 & 5 \\
\hline 2. & APO11.02 & 3,9 & 5 & 4 & 5 \\
\hline 3. & APO11.03 & 3,73 & 5 & 4 & 5 \\
\hline 4. & APO11.04 & 4,25 & 5 & 4 & 5 \\
\hline 5. & APO11.05 & 4,4 & 5 & 4 & 5 \\
\hline 6. & APO11.06 & 3,7 & 5 & 4 & 5 \\
\hline & ata-rata & 3,9 & 5 & 4 & 5 \\
\hline
\end{tabular}

Dari tabel di atas dapat disimpulkan bahwa pada proses ensure resource optimisation di PT. Napol Medan Berkah untuk kondisi saat ini (as is) memperoleh nilai 3,9 atau bisa dikatakan berada di tingkat kapabilitas level 4 yaitu Predictable Process. Artinya pada pada proses APO11 di PT. Napol Medan Berkah telah beroperasi dalam batas yang ditentukan untuk mencapai hasil prosesnya. Sedangkan, untuk kondisi yang diharapkan (to be) pada proses ensure resource optimisation di PT. Napol Medan Berkah memperoleh nilai 5 dengan tingkat kapabilitas level 5 yang dimana pada tahap ini harus diterapkan Optimising Process. Artinya pada proses APO11 di PT. Napol Medan diharapkan terus ditingkatkan menjadi memenuhi sasaran dan relevan dengan bisnis saat ini.

\subsection{Pencapaian Proses pada PT.Napol Medan Berkah}

Langkah selanjutnya setelah tin gkat kapabilitas pada setiap domain proses adalah mengecek secara bertahap indikator kapabilitas proses yang harus diraih oleh PT Napol Medan Berkah. Pada perhitungan menggunakan skala linkert didapatkan tingkat kapabilitas pada setiap proses, yaitu EDM04 saat ini berada pada level 2, APO11 saat ini berada pada level 2, EDM04 maka harus memenuhi capaian proses attibute dari level 1 sampai 2. Begitu juga dengan proses APO11 yang harus memenuhi capaian proses attribute dari level 1 sampai 2.

Pemeriksaan ini mengacu pada indikator kapabilitas proses yang terdapat pada COBIT 5. Indikator kapabilitas proses merupakan sarana 
untuk mencapai kemampuan yang diharapkan oleh PT Napol Medan Berkah.

Tabel 5. Pencapaian Level EDM04

\begin{tabular}{|c|c|c|c|c|c|c|c|c|c|c|}
\hline Proses name & $\begin{array}{c}\text { Level } \\
0\end{array}$ & Level & \multicolumn{2}{|c|}{ Level 2} & \multicolumn{2}{|c|}{ Level 3} & \multicolumn{2}{|c|}{ Level 4} & \multicolumn{2}{|c|}{ Level 5} \\
\hline \multirow{2}{*}{ EDM04 } & & PA & PA & PA & PA & PA & PA & PA & PA & PA \\
\hline & & 1.1 & 2.1 & 2.2 & 3.1 & 3.2 & 4.1 & 4.2 & 5.1 & 5.2 \\
\hline \multirow[t]{2}{*}{ Rating by Criteria } & & $\begin{array}{c}\mathrm{L} \\
87,5\end{array}$ & $\begin{array}{c}F \\
83,33\end{array}$ & $\mathrm{~L}$ & & & & & & \\
\hline & & $\%$ & $\%$ & $15 \%$ & & & & & & \\
\hline Capability & & 1 & 2 & 2 & & & & & & \\
\hline Level Achieved & & & & & & & & & & \\
\hline
\end{tabular}

Berdasarkan table di atas ini, dapat disimpulkan bahwa process performance mendapatkan hasil 87,5 \% Hal ini berarti termasuk dalam kategori Fully Archived (Tercapai penuh) dan pada atribut performance management didapatkan hasil $79,17 \%$ Sebagai bukti sudah terdapat beberapa dokumen. Sehingga proses tidak dapat dilanjutkan ke level selanjutnya atau Level 3. Karena syarat yang dibutuhkan untuk menlajutkan ke Level 3 adalah pada Level 2 harus masuk kategori Fully Achived (Tercapai penuh).

b. Pencapaian Level APO11

Tabel 6. Pencapaian Level APO11

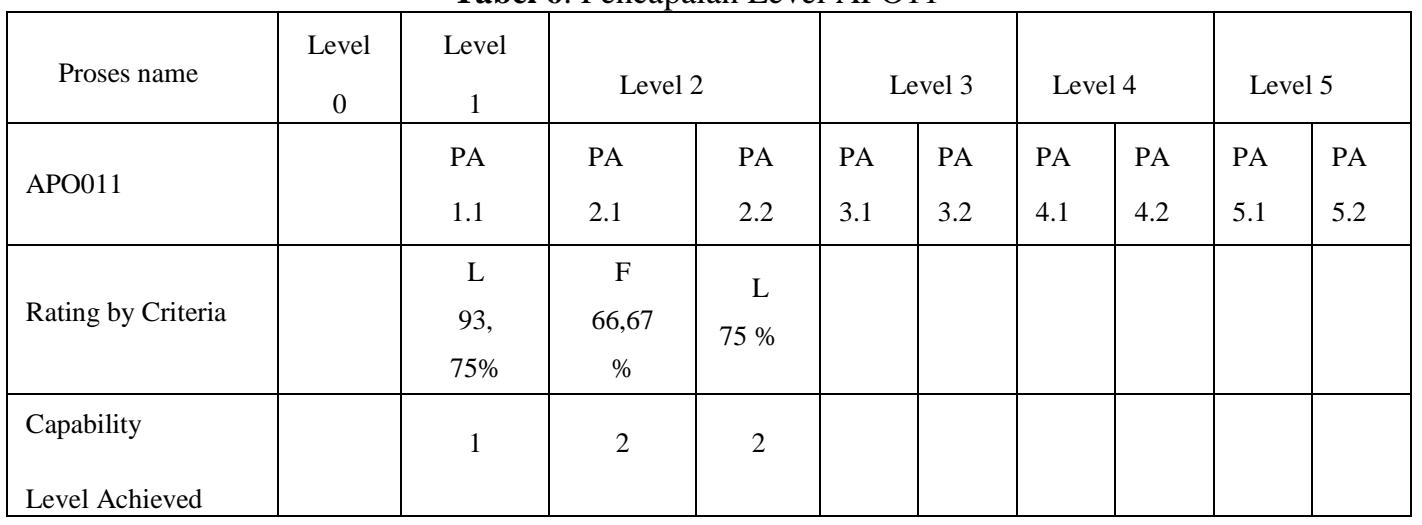

Berdasarkan table APO011 di atas ini, dapat disimpulkan bahwa process performance mendapatkan hasil 93,75 \% Hal ini berarti termasuk dalam kategori Fully Archived (Tercapai penuh) dan pada atribut performance management didapatkan hasil $70,84 \%$ Sebagai bukti sudah terdapat beberapa dokumen. Sehingga proses tidak dapat dilanjutkan ke level selanjutnya atau Level 3. Karena syarat yang dibutuhkan untuk menlajutkan ke Level 3 adalah pada Level 2 harus masuk kategori Fully Achieved (Tercapai Penuh).

\section{Kesimpulan}

Berdasarkan hasil penelitian yang telah dilakukan, dapat ditarik kesimpulan sebagai berikut : a. PT Napol Medan Berkah telah menerapkan tata kelola teknologi informasi pada level Defined Process. Hasil pengolahan kuisioner mendapati nilai rata- rata untuk tingkat kapabilitas adalah 3,9 dari rentang nilai 0 sampai 5. Artinya PT Napol Medan Berkah telah melakukan tata kelola teknologi informasi dengan baik.

b. Domain EDM04 dan APO011 berada pada nilai rata - rata tingkat kapabilitas 4 yang berarti pada umumnya proses telah dikelola secara berskala termasuk dalamnya kegiatan perencanaan dan monitoring. Dan diharapkan dapat mencapai hasil yang sesuai dengan memenuhi syarat indikator - indikator kapabilitas proses pada level 2 yang belum terpenuhi agar dapat menlajutkan ke level berikutnya. Seperti membuat dokumentasi 
analisis ide inovasi dan dokumen yang menjelaskan mengenai pengelolaan sumber daya.

\section{DAFTAR PUSTAKA}

[1] Putra R., Evaluasi Tata Kelola Teknologi Informasi Berbasis COBIT 5 dalam Pelayanan Sistem Informstasi Akademik di Universitas Pendidikan Ganesha, Program Studi Magister Teknik Informatika Program Pascasarjana Universitas Atmajaya Yogyakarta, Yogyakarta. 2015.

[2] Handayaningsih S., Perancangan Model Tata Kelola Teknologi Informasi Berbasis Cobit 4.1 pada Proses Mengelola Sumber Daya Manusia IT (Studi Kasus Bagian Pengelolaan Data Kab, Kendal),Program Studi Teknik Informatika Universitas Ahmad Dahlan, Yoyakarta. 2013.

[3] Wardani S., Audit Tata Kelola Teknologi nformasi Menggunakan Framework COBIT dengan Model Maturity Level (Studi Kasus Fakultas ABC). 2014.

[4] Syaroh S., Audit Sistem Informasi Call Center Pada PT Arga Bangun Bangsa (ESQ Learship Center) dengan menggunakan framework COBIT, Universitas Islam Negeri Syarif Hidayatullah Jakarta, Jakarta. 2011.

[5] Miranti A., Tata Kelola Teknologi Informasi Menggunakan Framework COBIT 5. Universitas Islam Negeri Syarif Hidayatullah, Jakarta. 2019.

[6] Nugroho H. Perancangan Model Kapabilitas Optimasi Sumber Daya TI Berdasarkan
COBIT 5 Process Capability Model. Program Studi Teknik Komputer Politeknik Telkom. 2013.

[7] Ajimasmoto F., Analisis Domain Proses COBIT Framework 5 Pada Sistem Informasi Worksheet (Studi Kasus: Perguruan Tinggi STMIK, Politeknik Palcomtech). Palembang. 2017.

[8] Maskur, Adolong N., Makodongan R., Implementasi Tata Kelola Teknologi Informasi Menggunakan Framework COBIT 5 di BPMPTSP Bone Bolango, Gorontalo. 2017.

[9] Pragita C., Firdaus Y., Guslinar P., Analisis Audit Sistem Informasi pada Domain APO (Align, Plan, and Organise) Manage Quality dengan menggunakan Cobit Framework (Studi Kasus : Direktorat Sistem Informasi Universitas Telkom). Departemen Teknik, Fakultas Informatika, Universitas Telkom, Bandung. 2014.

[10] Hakim A., Saragih H., Suharto A., Evaluasi Kelola Teknologi Dengan Framework COBIT 5 Di Kementrian ESDM (Studi Kasus pada Pusat Data dan Teknologi Informasi ESDM). Program Studi Teknik Informatika, Sekolah Tinggi Manajemen Informatika dan Komputer Eresha. 2014.

[11] Ryan Randi S., Darwis D., Surya Indra G.,. Audit Tata KelolaTeknologi Informasi Menggunakan Framework COBIT 5 (Studi Kasus: Balai Besar Perikanan Budidaya Laut Lampung). Universitas Teknokrat Indonesia Labuhanratu, Bandarlampung. 2018. 